\begin{tabular}{c|c|c}
\hline JURNAL PENELITIAN KESMASY & VOL. 1 NO. 2 & EDITION: NOVEMBER 2018 - \\
\hline & http://ejournal.delihusada.ac.id/index.php/JPKSY & \\
\hline RECEIVED: 12 Desember 2018 & REVISED: 18 FEBRUARI 2019 & ACCEPTED: 18MARET 2019 \\
\hline
\end{tabular}

\title{
HUBUNGAN LINGKAR PINGGANG DENGAN KEJADIAN DIABETES MELLITUS PADA PASIEN USIA 30 SAMPAI 50 TAHUN DI PUSKESMAS KOTA MATSUM MEDAN
}

\author{
Dian Afriandi \\ Universitas Islam Sumatera Utara, JI. STM No. 77 Medan \\ dian.afriandi@fk.uisu.ac.id
}

\begin{abstract}
The purpose of this study was to identify blood sugar levels in obese patients in the Matsum City Public Health Center Medan and to analyze the relationship between waist circumference and the incidence of type 2 diabetes mellitus in patients at the Matsum City Public Health Center in Medan. This research was conducted by analytic survey with a Cross Sectional design where all data concerning research variables were collected by approaching, observing or collecting data at a time. The sample used was 69 people. The results in this study found that there was a relationship between waist circumference and the incidence of diabetes mellitus in patients in the Work Area of Kota Matsum Health Center, Medan, North Sumatra.
\end{abstract}

Kata Kunci : Diabetes Mellitus,LingkarPinggang

\section{PEndahuluan}

Indonesia

kinitelahmendudukirangkingkeempatjumlahpe nyandang diabetes terbanyaksetelah India.BerdasarkanhasilRisetKesehatanDasarya ng dirilis tahun 2007, angkaprevalensi diabetes mellitus yang tertinggiterdapat di provinsi Kalimantan Barat dan Maluku Utara yang masing-masing $11.1 \%$, diikuti Riau $10.4 \%$ dan Nangroe Aceh Darusalam 8.5\%. Sementaraitu,prevalensi diabetes mellitus (DM)terendahada di provinsi Papua 1.7\% dandiikutioleh Nusa Tenggara Timur (NTT) 1.8\% (Depkes, 2008).

PrevalensiToleransiGlukosaTerganggutertinggi di Papua Barat $21.8 \%$, diikutiSulawesi Barat17.6\%, danSulawesi Utara17.3\%, sedangkanyang terendahadalah di Jambi $4 \%$, diikuti NTT 4.9\%. Angkakematianakibat DM dialami mereka yang berusia 45-54 tahun, dengan karakteristikberdasarkan daerahperkotaansebesar $14.7 \%$ sedangkan di daerahpedesaansebesar 5.8\%. (Depkes,2008).

DM merupakanpenyakit metabolic yang diletupkanolehinteraksiberbagaifaktor: genetik,imunologik,lingkungan,dangayahidup. Penyakitiniditandaidenganhiperglikemia, suatukondisi yang terjalineratdengankerusakanpembuluhdarahbe sar (makrovaskuler) maupunpembuluh dara kecil (mikrovaskuler),yang merupakan kegagalan, kerusakan, ataupungangguanfungsi organ (Qian\&Eaton, 2000).Perubahanmikrovaskulerdiyakiniparaahli dapat terjadi ketikakadargula diabetes melebihiangka $126 \mathrm{mg} / \mathrm{dL}$, sementarakelainanmakrovaskulerbaruakan munculsetelah beberapa tahun (Skyler, 1996). Perubahanmikrovaskulerpada bagian yang menyentuhmatadanginjal

dapatberakhirsebagairetinopatidannefropati.Se mentaraitu, gangguanmakrovaskulerjuga dapat terjadi pada system kardiovaskulerdantidakjarangberujungsebagaia teroskelosis (Arisman, 2013)

Padapenderita diabetes dapat juga terjadi masalahdengan insulin, baik akibat jumlah insulin yang kurangatauefekkerja insulin dalam memasok gulakedalamselyang tidaksempurnaataumungkinjugakarenamasalah kedua-duanya.Akibatnya, guladarahmenjadi 


\begin{tabular}{c|r|r}
\hline JURNAL PENELITIAN KESMASY & VOL. 1 NO. 2 & EDITION: NOVEMBER 2018 - \\
\hline & http://ejournal.delihusada.ac.id/index.php/JPKSY & \\
\hline RECEIVED: 12 Desember 2018 & REVISED: 18 FEBRUARI 2019 & ACCEPTED: 18MARET 2019 \\
\hline
\end{tabular}

sangattinggi yang merupakan cirikhasdiabetes.Kadar Gula yang tiggiinilah yang dapatmenyebabkankomplikasipada organ yang lain (Kurniadi\&Nurrahmani, 2014).

Padakegemukanatauobesitas,sel-sellemak yang menggemukakanmenghasilkanbeberapazat yang digolongkansebagaiadipositokin yang jumlahnyalebihbanyakdibandingkan pada mereka yang tidakgemuk. Zat-zatitulah yang menyebabkantimbulnyaresistensi insulin.Namun, di antarbeberapaadipositokin yang 'jahat' , terdapat pula yang bersifatbaik, yaituadiponektin, dimanazatinibermanfaat mencegahtimbulnyaresistensi insulin. Sayangnyakadaradiponektininijustruturunsewa ktusellemakmelimpah yang menjadi penyebab kegemukan. Anehnyasellemak yang paling banyakmenghasilkanadipositokinadalah yang melapisi organ-organ di dalamperut.Olehkarenaitu, obesitasjuga dapat berdampakburukterhadap diabetes dapatditentukanoleh ukuran lingkarpinggang yang besar.

\section{METODE}

Penelitianinidilakukandengancara

survey analitikdenganrancangan Cross

Sectionaldimanasemua data yang menyangkutvariabelpenelitiandikumpulkanden gancarapendekatan, observasiataupengumpulan data sekaligussuatusaat. Penelitianinidilakukan di Wilayah KerjaPuskesmas Kota Matsum Medan Sumatera

Utara.Sampeldalampenelitianinidiambildenganc ara Purposive Sampligberdasarkankriteria yang telahdibuatolehpenelitidansampelsebanyak 69 orang. Instrument yang digunakandalampenelitianiniyaitumeterandanal atukurkadarguladarahsertalembarObservasi. Kegiatanpenelitiandilakukandenganterlebihdah ulumengambil data rekam medic pasien Diabetes Mellitus di puskesmaskotamatsum, kemudianmendatangisuubjekdanmemintapers etujuankepadasubjek. Teknikpengumpulan data denganmelakukanpengukuranlingkarpinggang padapasienobesitasdanmengukurkadarguladar ahsewaktupasien.

Setelahituhasildaripengukuranakandicatatdala mlembarobservasi.

\section{HASIL PENELITIAN}

Hasil penelitian menunjukkan bahwa dari subjekpenelitianyang berjumlah 69 orang, dperoleh pasien yang berumurkurang dari 35 tahunsebanyak 20 orang $(28,98 \%)$, usia $36-$ 45 tahunsebanyak 26 orang $(37,68 \%)$, danusia 46-50 tahunsebanyak 23 orang $(30,43 \%)$ sebagaimana ditunjukkanpada tabel 1.

Tabel.1 FrekuensiDistribusiBerdasarkanUmur

\begin{tabular}{ccc}
\hline Umur & $\mathbf{n}$ & $\mathbf{( \% )}$ \\
\hline$<35$ tahun & 20 & 28.98 \\
$36-45$ tahun & 26 & 37.68 \\
$46-50$ tahun & 23 & 30.43 \\
Total & $\mathbf{6 9}$ & $\mathbf{1 0 0 . 0}$ \\
\hline
\end{tabular}

Selain umur, karaktersitik pasien juga dibedakan berdasarkan jenis kelaminnya.menunjukkanjeniskelaminlakilakiberjumlah 32 responden $(43,67 \%)$ sedangkanperempuanberjumlah 37 responden $(53,63 \%)$ seperti ditunjukkan dalam tabel 2 .

Tabel.2

FrekuensiDistribusiBerdasarkanJenisKelamin

\begin{tabular}{lcc}
\hline \multicolumn{1}{c}{ JenisKelamin } & $\mathbf{n}$ & $\mathbf{( \% )}$ \\
\hline Laki-laki & 32 & 46.37 \\
Perempuan & 37 & 53.63 \\
Total & $\mathbf{6 9}$ & $\mathbf{1 0 0 . 0}$ \\
\hline
\end{tabular}

Adapun terkait ukuran lingkar pinggang, diketahui 23 respondenmasukdalamgolongandenganlingkar pinggang normal (33,3\%) dan 46 respondendenganlingkarpinggangtidak normal $(46,7 \%)$ seperti pada tabel 3 .

Tabel.3

FrekuensiDistribusiBerdasarkanLingkarPinggan

$\mathrm{g}$

\begin{tabular}{lcc}
\hline LingkarPinggang & $\mathbf{n}$ & $\mathbf{( \% )}$ \\
\hline Normal & 23 & 33.3
\end{tabular}




\begin{tabular}{c|c|c}
\hline JURNAL PENELITIAN KESMASY & VOL. 1 NO. 2 & EDITION: NOVEMBER 2018- \\
\hline & http://ejournal.delihusada.ac.id/index.php/JPKSY & \\
\hline RECEIVED: 12 Desember 2018 & REVISED: 18 FEBRUARI 2019 & ACCEPTED: 18MARET 2019 \\
\hline
\end{tabular}

\begin{tabular}{|c|c|c|c|c|c|}
\hline Tidak Normal & 46 & 46.7 & Resiko DM & 26 & 37.7 \\
\hline Total & 69 & 100.0 & DM & 27 & 39.1 \\
\hline & & & Total & 69 & 100.0 \\
\hline
\end{tabular}

Berdasarkan hasil pemeriksaan terhadap kadar gula darah pasien diperoleh bahwa 16 respondenmasukdalamgolonganguladarah normal $\quad(23,2 \%), \quad 26$ respondenmasukdalamgolonganresiko DM $(37,17 \%)$, dan 27 respondenmasukdalamgolongan DM $(39,1 \%)$ yang ditunjukkan oleh tabel 4.

Responden yang tergolongDM denganlingkarpinggang normal sebanyak 2 responden $(8,7 \%)$, resiko DM sebanyak 12 responden $(52,2 \%)$, dankategori Non-DM sebanyak 9 responden (39,1\%).Responden yang

termasukdalamgolonganDMdenganLingakarpin ggangtidak normal sebanyak 25 responden $(54,3 \%)$, resiko DM sebanyal 14 responden (30,14\%), dan Non-DM sebanyak 7 responden $(15,2 \%)$ sebagaimana ditunjukkan oleh tabel 5.

Tabel.5 HubunganLingkarPinggangdenganKejadian Diabetes Mellitus

\begin{tabular}{|c|c|c|c|c|c|c|c|c|c|}
\hline \multirow[t]{3}{*}{ LingkarPinggang } & \multicolumn{8}{|c|}{ Kriteria Kadar GulaDarah } & \multirow[t]{3}{*}{ P Value } \\
\hline & \multicolumn{2}{|c|}{ DM } & \multicolumn{2}{|c|}{ Resiko DM } & \multicolumn{2}{|c|}{ Non- DM } & \multicolumn{2}{|c|}{ Total } & \\
\hline & $\mathbf{n}$ & $\%$ & $\mathbf{N}$ & $\%$ & $\mathbf{n}$ & $\%$ & $\mathbf{N}$ & $\%$ & \\
\hline Normal & 2 & 8.7 & 12 & 52.2 & 9 & 39.1 & 23 & 100.0 & \multirow{3}{*}{0,001} \\
\hline Tidak Normal & 25 & 54.3 & 14 & 30.14 & 7 & 15.2 & 46 & 100.0 & \\
\hline Total & 27 & 39.1 & 26 & 37.7 & 16 & 23.2 & 69 & 100.0 & \\
\hline
\end{tabular}

orang, dengankadarguladarah Normal sebanyak 2 responden $(6,3 \%)$, resiko DM

HasilUjichi-squarediperoleh $p=0,001<0,05$ ), maka dapat disimpulkan bahwa terdapathubungan yang bermaknaantarabesarlingkarpinggangdengank ejadian diabetes mellitus sebagaimana dapat dilihat pada tabel 6 .

Tabel.6 HubunganJenisKelamindengan Kadar GulaDarah

\begin{tabular}{|c|c|c|c|c|c|}
\hline & & \multicolumn{3}{|c|}{$\begin{array}{c}\text { Kriteria KGD } \\
\text { Total }\end{array}$} & \multirow{2}{*}{ Total } \\
\hline & & DM & $\begin{array}{c}\text { Resiko } \\
\text { DM }\end{array}$ & Non-DM & \\
\hline \multirow{4}{*}{ 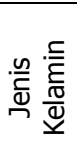 } & \multirow{2}{*}{$\mathrm{L}$} & 15 & 15 & 2 & 32 \\
\hline & & $46,9 \%$ & $46,9 \%$ & $6,3 \%$ & $100,0 \%$ \\
\hline & \multirow{2}{*}{$P$} & 12 & 11 & 14 & 37 \\
\hline & & $32,4 \%$ & $29,7 \%$ & $37,8 \%$ & $100,0 \%$ \\
\hline \multirow{2}{*}{\multicolumn{2}{|c|}{ Total }} & 27 & 26 & 16 & 69 \\
\hline & & $39,1 \%$ & $37,7 \%$ & $23,2 \%$ & $100,0 \%$ \\
\hline
\end{tabular}

BerdasarkanTabel

6.diketahuibahwarespondendenganjeniskelami nlaki-lakisebanyak sebanyak 15 responden $(46,9 \%)$, dan DM sebanyak 15 responden (46,97\%). Responden yang berjeniskelaminperempuansebanyak 37 responden,dimanarespondenperempuandenga nkadarguladarah normal sebanyak 14 responden $(37,8 \%)$, resiko DM sebanyak 11 responden $(29,7 \%)$, danrespondendengan DM sebanyak 12 responden (32,4\%).

Dari hasilpenelitian yang dilakukan,didapatibahwarespon yang Pterbanyakdalampenelitianiniadalahperempuany aitusebanyak 37 respondendanrenspondenlakilakisebanyak 32 responden.HasilUji Chi-Square didapati $p=0,008(p<$

0,008 ), makadapatdisimpulkanbahwaterdapathu bungan yang bermaknaantarabesarlingkarpinggangdengank ejadian diabetes mellitus.

\section{PEMBAHASAN}

Hasilpenelitianinimenunjukkan bahwa ukuraningkarpinggangdengankadarguladarahp 


\begin{tabular}{c|r|c}
\hline \multirow{2}{*}{ JURNAL PENELITIAN KESMASY } & VOL. 1 NO. 2 & EDITION: NOVEMBER 2018 - \\
\hline & http://ejournal.delihusada.ac.id/index.php/JPKSY & \\
\hline RECEIVED: 12 Desember 2018 & REVISED: 18 FEBRUARI 2019 & ACCEPTED: 18MARET 2019 \\
\hline
\end{tabular}

rosprandialmerupakansalahsatufaktorpenyeba b diabetes mellitus. Umumnya ukuran lingkar pinggang seseorang dipengaruhi oleh lemak yang terdapat didalamnya akibat makanan dan pola makan yang buruk. Memakan makanan manis, berlemak dan asin secara signifikan berhubungan dengan kejadian DM. Konsumsi makanan asin misalnya dapat meningkatkan berisiko DM sebesar 2,62 kali. Sebaliknya, mengkonsumsi makanan manis dan berlemak malah berisiko lebih rendahterkena DM (Nur dkk, 2016).

Guladarahadalahbahanbakartubuh yang dibutuhkanuntukkerjaotak,system

saraf,danjaringantubuh lain. Guladarah yang terdapat di dalamtubuhdihasikanolehmakanan yang

mengandungkarbohidrat,protein, danlemak.Pen ingkatankadarguladarah

(hiperglikemiadandiabetes mellitus) tidakbagusuntukkesehatan,kadarguladarahseh arusnyaberadadalamposisi normal agar kerja organ-organ tubuhtetapsehatdan normal.

Hasilpenelitianinimenunjukkanbahwajeniskela minlaki-lakilebihbanyakmenderita diabetes mellitus daripadaperempuan, dimana laki-laki berisiko diabetes melitus sebesar 2,48 kali lebih besar. Selain itu periode umur juga memberikan pengaruh yang signifikan, dimana mereka yang berusia lebih dari 50tahun berisiko diabetes melitus sebesar 2,16 kali. Pola hidup sehat dan pola makan seimbang dianjurkan agar terhindar daripenyakit DM (Nur, 2016) Perbedaanresikoinidipengaruhioehdistribusilem aktubuh. Padalaki-

laki,penumpukanlemakterkonsentrasi di sekitarperutsehinggamemicuobesitassentral yang lebihberisikomemicugangguanmetabolism (Isnaini \& Ratnasari, 2018).Dengan kata lain, laki-lakilebihrentanterhadap diabetes.

\section{KESIMPULAN}

Berdasarkanhasilpenelitian yang telahdilakukan di Wilayah KerjaPuskesmaskotaMatsum Medan Sumatera Utara,makadapatditarikkesimpulan:

1. Didapatigambaranpasien yang memilikilingkarpinggangtidak normal di Wilayah KerjaPuskesmas Kota Matsum
Medan Sumatera Utara dengankriteriaterbanyakadalahpasiendeng an Diabetes Mellitus.

2. Terdapathubunganlingkarpinggangdengan kejadian diabetes mellitus padapasien di Wilayah KerjaPuskesmas Kota Matsum Medan Sumatera Utara.

Saran yang diberikan berkaitan dengan hasil penelitian ini adalah:

1. Bagipuskesmaskotamatsumperlumelakuka $\mathrm{n}$ program pemberdayaankesehatanbagimasyarakat yang menderita diabetes mellitus danpasiendenganlingkarpinggangtidak normal untukmengurangijumlahpasien yang menderita Diabetes Mellitus di masa yang akandatang

2. Bagipetugaspuskesmasperlumelakukankon selingdanmemberipengetahuankepadamas yarakatkhususnyapenderita Diabetes Mellitus danpasienlingkarpinggangtidak normal

bahwapentinguntukmenjagakesehatanunt ukmencegahkomplikasidari Diabetes Mellitus

3. Bagimasyarakatwilayahkotamatsumperlum emperhatikankesehatandanmenjaga diameter lingkarpinggangkhususnyapasien yang mempunyailingkarpinggang yang berlebihandapatmelakukanpenurunanberat badanbaikdenganmelakukanolahraga, aktifi tasfisik, mengurangikonsumsimakanan yang mengandunglemaklebih.

\section{DAFTAR PUSTAKA}

Arisman. 2013. Obesitas, Diabetes Melitus, danDislipidemia: Konsep: Teori, danPenangananAplikatif Seri Buku Ajar IImuGizi. Jakarta: EGC

Departemen Kesehatan, R.I. 2008. Riset Kesehatan Dasar Tahun 2007. Jakarta: Badan Penelitian dan Pengembangan Kesehatan.

Isnaini, N., \& Ratnasari. 2018. Faktor risiko mempengaruhi kejadian Diabetes mellitus tipe dua. Jurnal Keperawatan 


\begin{tabular}{c|c|c}
\hline JURNAL PENELITIAN KESMASY & VOL. 1 NO. 2 & EDITION: NOVEMBER 2018 - \\
\hline & http://ejournal.delihusada.ac.id/index.php/JPKSY & \\
\hline RECEIVED: 12 Desember 2018 & REVISED: 18 FEBRUARI 2019 & ACCEPTED: 18MARET 2019 \\
\hline
\end{tabular}

dan Kebidanan Aisyiyah, Vol 14 (1), pp.59-68

Kurniadi\&Nurrahmani. 2014. Stop Diabetes, Hipertesi, Kolestro/Tinggi, JantungKoroner. Yogyakarta: Istana Media.

Nur, A., Fitria, E., Zulhaida A., \& Hanum, S. 2016. Hubungan Pola Konsumsi dengan Diabetes Melitus Tipe-2 pada Pasien Rawat Jalan di RSUD Dr. Fauziah BireuenProvinsi Aceh.Media Litbangkes, Vol. 26 (3), p. 145-150.

Qian, M. \& Eaton, J.W. 2000. Glycochelates and the etiology of diabetic peripheral neuropathy. Free Eadic. Biol. Med., Vol. 28 (4), p. 652-6.

Skyler, J.S. 1996. Diabetic Complications: The Impotrance of Glucose Control. Endocrinol Metab. Clin. North Am., Vol 25, p. 243-254. 